\title{
Antinuclear antibody-negative systemic lupus erythematosus-how common?
}

\author{
KC McHARDY,* CHW HORNE, $\dagger$ JAN RENNIE, \\ From the University Departments of Therapeutics and *Clinical Pharmacology and $\dagger$ Pathology, Foresterhill, \\ Aberdeen and the $\ddagger$ Division of Rheumatology, City Hospital, Aberdeen
}

SUMMARY A review of five years' DNA-binding antibody results in a routine service laboratory revealed 38 patients who had high DNA-binding capacity (DNA-bc) but no antinuclear antibodies (ANA). On retrospective case note analysis, 22 patients $(58 \%)$ were thought to have systemic lupus erythematosus (SLE), although only six (16\%) fulfilled the preliminary classification criteria of the American Rheumatism Association (ARA). Our findings indicate that ANA-negative SLE is commoner than generally realised and lead us to recommend the measurement of DNA-bc in every case where clinically appropriate.

Current clinical teaching suggests that ANA are present in at least $98 \%$ of cases of SLE, ${ }^{2}$ and that the measurement of DNA-bc is more appropriate as a secondary, specific diagnostic test on ANA-positive sera. The usefulness of the ANA test as a screening procedure for the detection of sera with high DNA-bc has recently been evaluated ${ }^{3}$ and its worth established in this context. However, it is possible that some cases of SLE which are not associated with ANA will be missed if the ANA test alone is carried out. ${ }^{3}$ Antinuclear antibody-negative SLE has been implied, if not directly considered, in many studies of SLE over the years. ${ }^{4-6}$ Two series citing ten ${ }^{7}$ and eight $^{8}$ cases, respectively, of ANA-negative SLE have drawn more direct attention to this entity and Maddison $\mathrm{et} \mathrm{al}^{9}$ recently presented data on 66 cases of SLE with serological abnormalities but negative ANA tests. In each study the cases were collected over a number of years as being atypical members of larger series of ANA-positive lupus.

The present study approaches ANA-negative SLE from a different angle in beginning with an abnormal laboratory finding. Review of DNA-bc results since the inception of the assay in 1976 as a routine laboratory test in Aberdeen showed a number of sera with markedly raised titres of antiDNA antibodies, but no detectable ANA. A high DNA-bc is probably the most specific laboratory test for diagnosing SLE $^{1011}$ although El-Ghobarey's study ${ }^{3}$ showed that only $87 \%$ of cases with DNA-bc greater than 30 units $(\mathrm{U}) / \mathrm{ml}$ had SLE. We present here our findings

Accepted for publication 24 February 1982 following a retrospective case note analysis on 38 patients who demonstrated a high DNA-bc in the absence of ANA.

\section{Subjects and methods}

The subjects consisted of 38 patients who had been in the care of various clinicians in Grampian Health Board hospitals and were therefore drawn from a population of approximately 500000 . Ages ranged from two to $84 \mathrm{yr},(\overline{\mathrm{x}}=50 \mathrm{yr})$. Twenty-two were female. All subjects had consistently negative ANA tests $(\bar{x}=4 \cdot 1$ tests/subject $)$, and had a recorded DNA-bc of $40 \mathrm{U} / \mathrm{ml}$ or greater. The DNA-bc assay had been performed one to eight times per patient $(\bar{x}=2 \cdot 64)$ and was greater than $40 \mathrm{U} / \mathrm{ml}$ on one to four occasions per patient $(\bar{x}=1 \cdot 77)$. Fourteen patients had a single result over $40 \mathrm{U} / \mathrm{ml}$; the assay had not been repeated in five of these.

Antinuclear antibody tests were carried out by the method of Beck $^{12}$ using an indirect immunofluorescence technique on a substrate of rat liver slices at a serum dilution of $1 / 16$. The DNA-binding capacities were measured using the antiDNA kit (RC Amersham) based on the method of Wold et al,,$^{13}$ which is a specific radioimmunoassay using ammonium sulphate precipitation of ${ }^{125}$ I-labelled, double-stranded DNA. The manufacturers suggest a normal range, subject to interlaboratory variation, of $0-10 \mathrm{U} / \mathrm{ml}$, and $25 \mathrm{U} / \mathrm{ml}$ is the level above which the diagnosis is "largely confined" to SLE. ${ }^{14}$

After initial perusal of the case histories we eliminated those in which there was insufficient 1118 
evidence to support a diagnosis of SLE. The clinical details in the remainder were then compared to the American Rheumatism Association (ARA) preliminary classification ${ }^{15}$ criteria for SLE, substituting a high DNA-bc for positive LE cell test and "Albustix (Ames) ${ }^{++}$" for "proteinuria $>3.5 \mathrm{~g} /$ day". The 14 ARA criteria were devised to allow more objective classification of patients for the purpose of clinical trials, population surveys etc, and a patient who exhibits four or more criteria, simultaneously or serially, is said to have SLE. Their use is widespread but of limited value in that many well established features of SLE are completely omitted while others appear in a very precise and over-restrictive way. It has been repeatedly stressed that fulfilment of four ARA criteria is not necessary to make a diagnosis. ${ }^{16}$ To allow a clinically more comprehensive assessment of our cases we further modified the original ARA list to that shown in Table 1 , and compared the clinical details, in turn, to these amended criteria.

\section{Table 1 Expanded list of SLE features based on ARA list}

\begin{tabular}{rlrl}
\hline${ }^{*} 1$ & Rash (incl butterfly, livedo & 9 & False + ve syphilis serology \\
& reticularis, vasculitis). & ${ }^{*} 10$ & Albustix ++ \\
2 & Discoid lupus & 11 & Granular urinary casts \\
3 & Raynaud's phenomenon & 12 & Pleurisy/pericarditis \\
4 & Alopecia & ${ }^{*} 13$ & Neuropsychiatric disorder \\
5 & Photosensitivity & 14 & Cytopenia \\
6 & Oral/nasal ulceration & ${ }^{1} 15$ & Fever \\
7 & Arthritis & ${ }^{*} 16$ & Ocular disease \\
${ }^{*} 8$ & DNA-bc $>40 \mathrm{U} / \mathrm{ml}$ & & \\
\hline
\end{tabular}

${ }^{*}$ Denotes changes from original ARA list.

Table 2 Clinical features of SLE in 22 patients

\begin{tabular}{lcll}
\hline DNA-bc $>40 U / m l$ & $22(100 \%)$ & Raynaud's & $3(14)$ \\
Arthritis & $15(68)$ & Albustix ++ & $3(14)$ \\
Neuropsychiatric disorder & $14(64)$ & Photosensitivity & $2(9)$ \\
Haematological disorder & $8(36)$ & Alopecia & $2(9)$ \\
Fever & $8(36)$ & Granular casts & $2(9)$ \\
Pleurisy/pericarditis & $7(32)$ & Oral/nasal ulcers & $1(5)$ \\
Ocular problems & $7(32)$ & False + ve syphilis & - \\
Rashes & $5(23)$ & serology & \\
& & Discoid lupus & - \\
\hline
\end{tabular}

Table 3 Clinical pattern in patients with only three listed features of $S L E$

\begin{tabular}{|c|c|c|c|c|c|c|}
\hline Patient & 1 & 2 & 3 & 4 & 5 & 6 \\
\hline Raynaud's & - & - & + & - & - & - \\
\hline $\begin{array}{l}\text { Arthritis } \\
\text { Highest DNA - bc }\end{array}$ & + & + & + & + & - & - \\
\hline$(\mathrm{U} / \mathrm{ml})$ & 54 & 74 & 52 & 57 & 41 & 71 \\
\hline Proteinuria & - & - & - & - & - & + \\
\hline $\begin{array}{l}\text { Pleurisy } \\
\text { Neuropsychiatric }\end{array}$ & - & - & - & - & + & - \\
\hline disorder & - & - & - & + & + & + \\
\hline Cytopenia & + & + & - & - & - & - \\
\hline
\end{tabular}

Results

Review of the case notes suggested that $22(58 \%)$ of our cases had SLE and the clinical features in this group are shown in Table 2 . The remaining 16 cases did not have enough evidence to support this diagnosis.

Comparison with the ARA list, modifying only the criteria regarding LE cells and proteinuria, showed that only six cases $(16 \%)$ had four or more features of SLE, while the remaining $16(42 \%)$ whom we thought to have SLE had either two or three of the features listed. When the clinical data on these 22 cases were compared to the expanded list, 16 had between four and nine $(\bar{x}=5 \cdot 1)$ features of SLE and the remaining six had three features each. All in this latter group had, by definition, markedly raised DNA-bc and their other clinical features are shown in Table 3.

\section{Discussion}

A condition with manifestations as protean as SLE does not readily lend itself to objective analysis. The ARA criteria go part of the way towards allowing comparison of different groups but it is intellectually disquieting to accept that a patient with a butterfly rash, arthritis, positive WR and raised DNA-bc has the very same disease as another with alopecia, Raynaud's phenomenon, haemolytic anaemia and recurrent mouth ulcers, while conversely, a third patient with arthritis, DNA binding antibodies, mild proteinuria, mononeuritis, vasculitic rash and thrombocytopenia cannot be classified as a case of SLE. These examples underline the need to apply the ARA criteria sensibly and to accept their limitations. In their review of the use of the ARA criteria Canoso and Cohen ${ }^{16}$ state that a standard set of diagnostic (cf classification) criteria for SLE is unlikely to appear until a great deal more is known of the aetiology and pathogenesis.

In trying to evaluate our cases we have based assessment on the ARA criteria but have tried to broaden these to increase their clinical application. Initially two of the original criteria were modified. First, substitution of high DNA-bc, the most specific laboratory investigation, for the outdated LE cell test is widely accepted. Second, proteinuria greater than $3.5 \mathrm{~g} /$ day was replaced by "Albustix ${ }^{++}$", representing approximately $1.5 \mathrm{~g} /$ day of urinary protein. This semiquantitative method was employed as accurate quantification of proteinuria is seldom carried out; the lesser amount of protein loss was chosen as considerable degrees of renal damage can occur without a urinary protein loss ever approaching the demands of the ARA criteria. This point has been 
previously raised ${ }^{1617}$ and is supported, amongst others, by Pollak and colleagues ${ }^{18}$ whose patients with biopsy-proven lupus nephritis had proteinuria in excess of $200 \mathrm{mg} /$ day in only 48 of 77 cases. The ARA criteria with these modifications gave six patients with the requisite four, or more, criteria and a further 16 patients with a formally inadequate two or three features. The discrepancy between clinical and classification assessments was clearly due to the exclusion from the ARA list of a number of well recognised features of SLE which were exhibited by some of our patients. Fever has been described in $80-100 \% \%^{1920}$ of SLE patients and was seen in a number of ours. A range of neuropsychiatric problems far wider than "psychosis and convulsions" is now recognised ${ }^{2122}$ and it was of particular interest that depression which Bennett and his associates ${ }^{23}$ describe as the commonest disorder of mental function in SLE led to four of 22 in our clinical SLE group requiring formal psychiatric assessment. A variety of ocular problems is recognised ${ }^{24}$ and the $32 \%$ incidence of eye disorders in our patients compares well with overall figures in previous studies. ${ }^{2025}$ In assessing cutaneous manifestations we included, in addition to facial erythema, rashes such as livedo reticularis, vasculitis and maculopapular eruptions, all of which may be useful clinical pointers to a diagnosis of SLE. ${ }^{2026}$

Using our broadened list of clinical features of SLE (Table 1) we now have 16 patients with four or more features and a further six (Table 3 ) each with three features. Some additional points of interest in this latter group are: haematological disorder in patient 1 included temporally distinct thrombocytopenia and Coombs'-positive haemolysis; patient 2 had a spontaneous abortion and a puerperal exacerbation of arthritis; patient 3 had episodes of non-specific chest pain, required sedatives for "nerves" and had a period of weight-loss, diarrhoea and abdominal pain for which extensive investigation gave no diagnosis; patient 4 had recurrent paraesthesiae and a depressive illness culminating in a drug overdose, in addition to mild renal impairment for no apparent reason; patient 5 had periungual erythema, a diminished gas transfer factor with exertional dyspnoea and a history of musculoskeletal pains; patient 6 had recurrent myalgia and stiffness, headaches, steroid-responsive strokes, telangiectases, proteinuria of up to five grams per day with impaired creatinine clearance and a brother who during the last few months has developed SLE with ANA. Thus we support a diagnosis of SLE in 22 cases.

What of the other 16 patients with high DNA-bc but not thought to have SLE? In some the information in the case notes was simply inadequate to allow any conclusions. Three patients had liver disease, which can be associated with high DNA-bc. ${ }^{27}$ Some may be evolving cases of SLE in whom sufficient clinical features to allow diagnosis will only develop after a number of years. Of our six cases who fulfilled the ARA criteria, only four would have done so at the time of first detection of a high DNA-bc. Late development of ANA has been highlighted by Bohan $^{28}$ who described five cases of active SLE developing ANA for the first time, ten months to seven years after the initial diagnosis. From the outset we eliminated from further study any patient who had ever had a positive ANA result. The 38 patients included in the study had remained ANA-negative over follow-up periods ranging from nine to 40 months. Detection of cytoplasmic antibodies (Ro and La) ${ }^{929}$ may be an important serological feature of ANA-negative SLE and we are hoping to study these in our patients.

More extensive studies will be necessary before it can be determined whether or not ANA-negative SLE is clinically distinct from the seropositive variety. The prominent characteristics in Fessel's ${ }^{8}$ and Maddison's ${ }^{9}$ groups, respectively, differed from each other and were also at variance with the original ARA group. ${ }^{15}$ Our patients were different again, displaying a relatively low incidence of skin manifestations, alopecia, photosensitivity and cellular urinary casts (Table 2).

It remains to be seen how large the ANA-negative SLE group will become once it is actively sought. The prevalence of SLE is not known but using a suggested figure of one in $2000,{ }^{30}$ our half-million catchment population should contain around 250 cases of SLE. The 22 ANA-negative cases detected to date would represent $8.9 \%$, a much larger figure than the one or two per cent which we are led to expect. Furthermore, we have excluded levels of DNA-bc less than $40 \mathrm{U} / \mathrm{ml}$ from our study thus leaving out an unknown number of cases with significantly raised DNA-bc.

The diagnosis of SLE is often difficult; only seven of our 22 cases had been diagnosed by their attending physician. However, the potential benefits of making the correct diagnosis at an early stage are obvious and we therefore recommend the measurement of DNA-bc in every case where clinically appropriâte, regardless of the presence or absence of ANA.

We would like to thank the local Area Committee of Physicians for permission to include its members' patients in our study.

\footnotetext{
References

1 Mowat AG. Laboratory investigations for joint diseases. Medicine Magazine 3rd ser 1978;12:590-5.
} 
${ }^{2}$ Hughes GRV. Immunological tests in the rheumatic diseases. In: Connective tissue diseases 2nd ed. Oxford Blackwell Scientific Publications, 1979:256.

${ }^{3}$ El-Ghobarey AE, Sloane DJP, Whaley K. The clinical significance of the antinuclear antibody test as a screening procedure for DNA antibodies in SLE. Scott Med J 1980;25,4:293-8.

${ }^{4}$ Estes D, Christian CL. The natural history of systemic lupus erythematosus by prospective analysis. Medicine (Baltimore) 1971;50:85-95.

5 Bartholomew BA. Antinuclear antibody tests as a clinically selected screening procedure. Am J Clin Pathol 1974;61:495-9.

- Lee P. Urowitz MB, Bookman AAM, et al. Systemic lupus erythematosus: a review of 110 cases with reference to nephritis, the nervous system, infections, aseptic necrosis and prognosis. Q J Med 1977;46:1-32.

${ }^{7}$ Fessel WJ. ANA-negative systemic lupus erythematosus. Am J Med 1978;64:80-6.

${ }^{8}$ Gladman DD, Chalmers A, Urowitz MB. Systemic lupus erythematosus with negative LE cells and antinuclear factor. $J$ Rheumatol 1978;5:142-7.

- Maddison PJ, Provost TT, Reichlin M. Serological findings in patients with "ANA-negative" systemic lupus erythematosus. Medicine (Baltimore) 1981;60:87-94.

10 Pincus T, Schur PH, Rose JA, Decker JL, Talal N. Measurement of serum DNA-binding activity in systemic lupus erythematosus. N Engl J Med 1969;281:701-5.

"Hughes GRV, Cohen SA, Christian CL. Anti-DNA activity in systemic lupus erythematosus: a diagnostic and therapeutic guide. Ann Rheum Dis 1971;30:259-64.

12 Beck JS. Variations in the morphological pattern of auto-immune nuclear fluorescence. Lancet $1961 ; \mathrm{i}: 1203-5$.

13 Wold RT, Young FE, Tan EM, Farr RS. Deoxyribonucleic acid antibody: a method to detect its primary interaction with deoxyribonucleic acid. Science 1968;161:806-7.

14 Holian J, Griffiths ID, Glass DN, Maini RN, Scott JT. Human anti-DNA antibody: reference standards for diganosis and arrangement of systemic lupus erythematosus. Ann Rheum Dis 1975;34:438-43.

is Cohen AS, Reynolds WE, Franklin EC, et al. Preliminary criteria for the classification of systemic lupus erythematosus. Bull Rheum Dis 1971;21:643-8.

${ }^{16}$ Canoso JJ, Cohen AS. A review of the use, evaluations and criticisms of the primary criteria for the classification of systemic lupus erythematosus. Arthritis Rheum 1979;22: 917-21.

${ }^{17}$ Davis P, Atkins B, Josse RG, Hughes GRV. Criteria for classification of SLE. Br Med J 1973;iii:88-9.

18 Pollak VE, Pirani CL, Schwartz FD. The natural history of the renal manifestations of systemic lupus erythematosus. $J$ Lab Clin Med 1964;63:537-50.

19 Shearn MA, Pirofsky B. Disseminated lupus erythematosus: analysis of 34 cases. Arch Intern Med 1952;90:790-807.

20 Dubois EL, Tuffanelli DL. Clinical manifestations of systemic lupus erythematosus. $J A M A$ 1964;190:104-11.

21 Johnson RT, Richardson EP. The neurological manifestations of systemic lupus erythematosus. Medicine (Baltimore) 1968; 47:337-69.

22 Gibson T and Myers AR. Nervous system involvement in systemic lupus erythematosus. Ann Rheum Dis 1976;35;398-406.

${ }^{23}$ Bennett R, Hughes GRV, Bywaters EGL and Holt PJL. Neuropsychiatric problems in systemic lupus erythematosus. $B r$ Med J 1972;iv:342-5.

${ }^{24}$ Lachmann S, Hazleman B. Rheumatic disorders and the eye. Update 1976;13:367-87.

${ }^{25}$ Harvey A McG, Shulman LE, Tumulty PA, Conley CL, Schoenrich EH. Systemic lupus erythematosus: review of the literature and clinical analysis of 138 cases. Medicine (Baltimore) 1954;33:291-437.

${ }^{26}$ Winkelmann RK. Diagnosis and treatment of lupus erythematosus, dermatomyositis and scleroderma, with emphasis on cutaneous findings. J Chronic Dis 1961;13:401-10.

27 Jain S, Markham R, Thomas HC, Sherlock S. Double stranded DNA-binding capacity of serum in acute and chronic liver disease. Clin Exp Immunol 1976;26:35-41.

28 Bohan A. Seronegative systemic lupus erythematosus. J Rheumatol 1979;6:534-40.

${ }^{29}$ Provost TT, Reichlin M. Antinuclear antibody-negative systemic lupus erythematosus: Anti-Ro (SSA) and Anti-La (SSB) antibodies. J Am Acad Dermatol 1981;4:84-9.

${ }^{30}$ Fessel WJ. Systemic lupus erythematosus in the community. Arch Intern Med 1974;134:1027-35.

Requests for reprints to: Professor CHW Horne, Department of Pathology, University Medical Buildings, Foresterhill, Aberdeen AB9 2ZD, Scotland. 